\title{
Abortion laws reform may reduce maternal mortality: an ecological study in 162 countries
}

\author{
Su Mon Latt ${ }^{1 *}$, Allison Milner ${ }^{2}$ and Anne Kavanagh ${ }^{2}$
}

\begin{abstract}
Background: Unsafe abortion is one of the commonest causes of maternal mortality. Abortion-related maternal deaths are higher in countries with the most restrictive abortion laws. We assess whether maternal mortality varies within and between countries over time according to the flexibility of abortion laws (the number of reasons a woman can have an abortion).

Method: We conducted an ecological study to assess the association between abortion laws and maternal mortality in 162 countries between 1985 and 2013. Aggregate-level data on abortion laws and maternal mortality were extracted from United Nations (UN), and World Health Organization's (WHO) database respectively. A flexibility score of abortion laws (Score 0-7) was calculated by summing the number of reasons for which abortion was legally allowed in each country. The outcome was maternal mortality ratio (MMR), which represented maternal deaths per 100,000 live births. MMR was modelled as a continuous variable and flexibility score as an ordinal ranked variable (categories $0-7$ with 0 as the reference, and $\langle 3$ vs $\rangle=3$ ). We used fixed effects linear regression models to estimate the association between flexibility score and MMR, adjusting for gross domestic product per capita (GDP per capita), and time in five-year intervals.
\end{abstract}

Results: Compared to when a country's flexibility score was $<3$, maternal deaths were reduced by 45 per 100,000 live births (95\% Cl: -64, - 26) when the flexibility score increased $\geq 3$, after adjusting for the GDP per capita and five-year time intervals. With the exception of a flexibility score 6, MMR was lower when higher than zero. This may indicate the role of other country- specific effects.

Conclusion: This study provides evidence that abortion law reform in countries with restricted abortion laws may reduce maternal mortality.

Keywords: Maternal mortality, Abortion laws, Ecological study, Panel data, Policy

\section{Background}

Maternal mortality remains a global challenge, despite efforts to achieve Sustainable Development Goals (SDGs) three of reducing maternal mortality. There were over 300,000 maternal deaths in 2015 among WHO member countries, corresponding to an overall maternal mortality ratio (MMR) of 216 (Uncertainty Interval (UI), 207 to 249) per 100,000; 99\% of maternal deaths occur in developing regions [1]. Nearly $8 \%$ of

* Correspondence: drsumonlatt@gmail.com

${ }^{1}$ Melbourne School of Population and Global Health, The University of Melbourne, Melbourne, Australia

Full list of author information is available at the end of the article maternal deaths worldwide are abortion-related and $99.5 \%$ of these occurring in developing regions $[1,2]$.There is strong evidence linking unsafe abortions with increased maternal morbidity and mortality [3-7] and most abortionrelated maternal deaths are due to unsafe and illegal abortions [8]. Although the overall abortion rate has declined, the proportion of unsafe abortions is increasing, especially in developing regions [3]. Unsafe abortions are most common in countries with restrictive abortion laws [9]. This suggests that improving abortion law reform could reduce maternal mortality, however, we do not have a rigorous evidence-base on which to support this premise. 
Throughout the world, there is considerable variation in abortion laws. In countries such as Sierra Leone, Afghanistan, Nigeria, Lao, and Myanmar, abortion is only legally allowed if a woman is in life-threatening situations. The policies are least restrictive in developed countries such as Australia, France, Germany, Italy, Canada, and United States, where a woman can request legal abortion for a range of reasons including physical or mental health, rape, fetal impairments or economic conditions [10]. The disparity in abortion-related maternal mortality could partly be explained by differences in abortion laws with women in countries with more restrictive laws being less able (or unable) to access to reproductive health care and safe abortion services.

There is little or no research about abortion laws and their impact on maternal mortality. Most studies have assessed change in trends of maternal mortality within countries after legalization without accounting for the other factors, such as levels of female education, which also change with time. For example, Handerson et.al [11] conducted a retrospective medical chart review in Nepal after abortion law was reformed to legally permit abortion for rape or incest, physical or mental health reasons. They found that the reformation of abortion laws in Nepal appeared to be associated with a significant decline in the rate of abortion-related morbidities, such as serious infections and systematic complication. This study did not address possible impacts on maternal mortality [11]. Of those studies that have been conducted, most have found a significant decrease in maternal mortality when abortion laws became less restrictive [11-16]. However, one study conducted in Chile found that maternal mortality was decreased after abortion became completely illegal in Chile [13]. Only one study was conducted in more than one country, where changes in abortion laws and maternal mortality were assessed in Romania, South Africa, and Bangladesh [12]. This study found a downward trend in maternal mortality after the liberalization of abortion laws [12].

While existing studies provide weak evidence of an association between more flexible abortion laws and reduced maternal mortality, all but one have been conducted within one country and none of the studies take account of confounding variables that change over time such as economic conditions and female education. In order to fill this gap in research, we conducted an ecological analysis using data from 162 countries on abortion laws and maternal mortality between 1985 and 2013 to estimate the association between the flexibility of abortion laws and maternal mortality at a country level.

\section{Methods}

All data were at an aggregate level by country and year. The study population was selected from the WHO and
UN member countries with available data. The data on abortion laws were obtained from the United Nations (UN) Population Division Database [17] and maternal mortality data were obtained from the WHO Global Health Observatory Database [18]. Maternal mortality data was available for 183 countries between 1985 and 2013. There were 175 countries with data on abortion laws over the same time period. The final sample included 162 countries with information on both abortion laws and maternal mortality between 1985 and 2013. Data extraction was done by S.M in May 2016.

\section{Definition of variables}

Information on the source, definition, and completeness of data for the exposure, outcome and covariates are available in Additional file 1: Table S1.

\section{Exposure variable}

The exposure of interest was the flexibility of abortion laws in each country for each year. The United Nations Population Division database, which recorded abortion laws around the world from 1963 to 2013, [19] had yearly data on abortion law policies between 1985 and 2005 and two-yearly thereafter (2007, 2009, 2011, and 2013). These data were manually extracted on 10th March 2016 using the "manual data query" function from "World Population Policies" database [17]. We classified the abortion laws according to the abortion law categories of UN population policy database [17, 19]. Grounds for which abortion is legally allowed in the country were coded in the database as:

1) Intervention to save the life of the woman (life grounds)

2) Preservation of the physical health of the woman (narrow health grounds)

3) Preservation of the mental health of the woman (broad health grounds)

4) Termination of pregnancy resulting from rape or incest (juridical grounds)

5) Suspicion of fetal impairment (fetal defect)

6) Termination of pregnancy for economic or social reasons (social grounds)

7) Availability upon request: abortion permitted on all grounds

We summed the number of grounds/reasons for which abortion was legally allowed in each country from 1985 to 2013 to give a flexibility score ranging from zero to seven. A flexibility score of zero means abortion is not legally allowed for any reason and a flexibility score of seven means abortion is legally allowed for any of the aforementioned grounds. 


\section{Outcome variable}

The outcome was maternal mortality ratio (MMR), which is the number of maternal deaths per 100,000 live births [1] (Refer to Additional files 1, 2, 3 and 4). Maternal mortality ratios in reproductive-aged (15-49 years) women were accessed from the World Health Organization Global Health Observatory database [18]. MMR was analyzed as a continuous outcome variable. We used MMR rather than abortion-specific maternal mortality, as abortion is a highly sensitive issue, especially in countries with restrictive abortion laws, where abortion is only allowed for life-threatening conditions. As the medical professionals and women performed the induced abortions can be imprisoned in places where this is illegal, we anticipated underreporting for induced abortions and abortion-related maternal mortality in such countries. This was supported by a recent systematic review of the measurements of abortion-related maternal mortality, where the results indicated underestimation and misclassification of abortion-related maternal mortality due to poor quality measurement [20].

\section{Other covariates}

Data on potential confounders were also extracted from the United Nation Population Division database [17] and the World Bank database [21-24]. Covariates included: female primary completion rate (\%); female literacy rate (\%), health expenditure per capita (in US dollars), and Gross Domestic Product per Capita (GDP per capita in US dollars). Details of data sources and definitions can be found in Table 1 .

\section{Missing data}

Table 1 shows that there were high proportions of missing data for female primary education, female literacy rate and health expenditure per capita. There was high co-linearity between female literacy rate and female primary completion rate, and between GDP per capita and

Table 1 Data sources and Definitions

\begin{tabular}{|c|c|c|c|}
\hline Variable & Source & Definition & Time period \\
\hline $\begin{array}{l}\text { Female primary completion } \\
\text { rate (Female \%) }\end{array}$ & $\begin{array}{l}\text { The World Bank Education } \\
\text { database [21] }\end{array}$ & $\begin{array}{l}\text { Total number of new female entrants in the last } \\
\text { grade of primary education, regardless of age, } \\
\text { expressed as a percentage of the total female } \\
\text { population of the theoretical entrance age to the } \\
\text { last grade of primary. This indicator is also known } \\
\text { as "gross intake rate to the last grade of primary } \\
\text { education." } \\
\text { The ratio can exceed } 100 \% \text { due to over-aged and } \\
\text { under-aged children who enter primary school } \\
\text { late/early and/or repeat grades. }\end{array}$ & $\begin{array}{l}1985-2013 \\
\text { (50\% complete) }\end{array}$ \\
\hline $\begin{array}{l}\text { Female Literacy Rate (Female, } \\
\%)\end{array}$ & $\begin{array}{l}\text { The World Bank Education } \\
\text { database [22] }\end{array}$ & $\begin{array}{l}\text { Percentage of females age } 15 \text { and above who can, } \\
\text { with understanding, read and write a short, simple } \\
\text { statement on their everyday life. This indicator is } \\
\text { calculated by dividing the number of female literates } \\
\text { aged } 15 \text { years and over by the corresponding age } \\
\text { group population and multiplying the result by } 100 \text {. }\end{array}$ & $\begin{array}{l}1985-2013 \\
\text { (only } 10 \% \\
\text { complete) }\end{array}$ \\
\hline $\begin{array}{l}\text { Health Expenditure per capita } \\
\text { (current US\$) }\end{array}$ & $\begin{array}{l}\text { The World Bank health database } \\
\text { [23] }\end{array}$ & $\begin{array}{l}\text { Total health expenditure is the sum of public and } \\
\text { private health expenditures as a ratio of total population. } \\
\text { It covers the provision of health services (preventive } \\
\text { and curative), family planning activities, nutrition activities, } \\
\text { and emergency aid designated for health but does not } \\
\text { include provision of water and sanitation. Data are in } \\
\text { current U.S. dollars. }\end{array}$ & $\begin{array}{l}1995-2013 \\
\text { (60\% complete) }\end{array}$ \\
\hline Abortion law indicators & $\begin{array}{l}\text { United Nations Population Division } \\
\text { Database, Department of Economic } \\
\text { and Social Affairs [17] }\end{array}$ & Refer to the exposure variable. & $\begin{array}{l}\text { 1985-2013 } \\
\text { (100\% complete) }\end{array}$ \\
\hline Maternal mortality ratio & $\begin{array}{l}\text { World Health Organization (Global } \\
\text { Health Observatory Database) [18] }\end{array}$ & $\begin{array}{l}\text { Maternal mortality ratio (MMR) } \\
\text { Maternal mortality ratio is defined as maternal } \\
\text { deaths per } 100,000 \text { live births. }\end{array}$ & $\begin{array}{l}\text { 1985-2013 } \\
\text { (100\% complete) }\end{array}$ \\
\hline GDP per capita & $\begin{array}{l}\text { World bank, World Development } \\
\text { Indicator Database [24] }\end{array}$ & $\begin{array}{l}\text { GDP per capita is gross domestic product divided by } \\
\text { midyear population. GDP is the sum of gross value } \\
\text { added by all resident producers in the economy plus } \\
\text { any product taxes and minus any subsidies not included } \\
\text { in the value of the products. It is calculated without } \\
\text { making deductions for depreciation of fabricated assets } \\
\text { or for depletion and degradation of natural resources. } \\
\text { Data are in current U.S. dollars. }\end{array}$ & $\begin{array}{l}\text { 1985-2013 } \\
\text { (93\% complete) }\end{array}$ \\
\hline
\end{tabular}


health expenditure per capita. Therefore, we included the variables with the fewer missing values (Refer to Table 1) in the regression models described below (i.e. GDP per capita and female primary completion rate).

\section{Statistical analysis}

First, we present the summary statistic by five- year time intervals for MMR, flexibility score and GDP per capita. The dataset was treated as a "panel dataset" [25] because the variables were recorded for the 162 countries at different points of time (i.e. 1985 to 2013). We conducted fixed effects linear regression modelling to assess the association between flexibility score of abortion laws and MMR within country before and after adjustment for economic income level (GDP per capita) and female education (female primary completion). Models were fitted separately with or without female education because of the high proportion of missing data on this variable (50\%). We modelled the flexibility score as a seven-level categorical variable with zero as the baseline and also as a binary variable $<3$ vs 3 or more based on the distribution of the variable [26]. We also adjusted for time in five-year intervals to account for secular trends in maternal mortality and the flexibility score over time.

Fixed effects regression models have been widely used in ecological studies to analyze time series cross-sectional (panel) data [27, 28]. Fixed effects models assess withincountry differences (i.e. each country is its own control). For example, the difference in MMR within country when the flexibility score was zero compared to when greater zero. This approach removes confounding from variables that do not change over time [26] For example, ethnic and religious composition of a country may be relatively stable over time. The "Hausman Test" showed that fixed effects rather than random effects regression was required because there was evidence of significant unmeasured time-invariant confounding between countries [29]. All analyses of fixed effects regression models were undertaken in STATA version 13.0 using "xtreg,fe".

\section{Results}

The average MMR, average flexibility score, and average GDP per capita for each country are presented in Additional file 1: Table S1. Table 2 presents summary statistics for MMR, flexibility score and GDP in five-year intervals. MMR decreased over time and mean flexibility score increased slightly. In all time intervals, median estimates were less than mean MMR estimates, showing the positively skewed distribution of MMR.

In 1985, four countries had a flexibility score of zero (El Salvador, Guyana, Indonesia, and Malta), and in 2013, five countries had a flexibility score of zero

Table 2 Summary measures of MMR, flexibility scores and GDP per capita in 162 countries by five-year time intervals

\begin{tabular}{|c|c|c|c|c|c|c|c|}
\hline & & \multicolumn{6}{|c|}{ Time Interval } \\
\hline & & $1985-1989$ & 1990-1994 & $1995-1999$ & $2000-2004$ & $2005-2009$ & $2010-2013$ \\
\hline \multirow[t]{5}{*}{ MMR (Maternal deaths per 100,000 live births) } & Mean & 367 & 328 & 296 & 259 & 219 & 186 \\
\hline & Median & 124 & 97 & 88 & 74 & 67 & 59 \\
\hline & SD & 467 & 446 & 413 & 359 & 298 & 253 \\
\hline & Minimum & 5 & 4 & 4 & 3 & 3 & 3 \\
\hline & Maximum & 2558 & 2902 & 2895 & 2649 & 1986 & 1580 \\
\hline \multirow[t]{5}{*}{ Flexibility Score (0-7) } & Mean & 3.67 & 3.82 & 3.86 & 3.84 & 3.90 & 4.10 \\
\hline & Median & 3 & 3 & 3 & 3 & 4 & 4 \\
\hline & SD & 2.50 & 2.47 & 2.47 & 2.50 & 2.50 & 2.50 \\
\hline & Minimum & 0 & 0 & 0 & 0 & 0 & 0 \\
\hline & Maximum & 7 & 7 & 7 & 7 & 7 & 7 \\
\hline \multirow[t]{5}{*}{ GDP per Capita (current US\$) } & Mean & 4220 & 5386 & 6442 & 7353 & 11,310 & 14,367 \\
\hline & Median & 1179 & 1312 & 1633 & 1967 & 3467 & 5470 \\
\hline & SD & 6269 & 8667 & 10,119 & 11,625 & 17,250 & 20,958 \\
\hline & Minimum & 97 & 65 & 65 & 106 & 141 & 240 \\
\hline & Maximum & 31,664 & 45,935 & 53,358 & 74,970 & 104,841 & 113,726 \\
\hline \multirow[t]{5}{*}{ Female primary completion rate (Female, \%) } & Mean & 66 & 70 & 76 & 81 & 85 & 89 \\
\hline & Median & 71 & 81 & 88 & 94 & 95 & 97 \\
\hline & SD & 32 & 32 & 29 & 29 & 23 & 20 \\
\hline & Minimum & 4 & 6 & 7 & 13 & 20 & 26 \\
\hline & Maximum & 135 & 120 & 128 & 188 & 134 & 116 \\
\hline
\end{tabular}


(Chile, Dominican Republic, El Salvador, Malta, and Nicaragua). In 1985, 43 countries had a flexibility score of seven and this increased to 52 countries in 2013. Between 1985 and 2013, Finland had the lowest MMR (approximately five per 100,000 live births in 1985 and three per 100,000 live births in 2013). Sierra Leone had the highest MMR (approximately 2352 per 100,000 live births in 1985 and 1460 per 100,000 live births in 2013).

The specific reasons allowed for legal abortions in each flexibility score (Score 0-7) were also assessed (See Additional file 1: Table S2). For example, for a flexibility score of two, the combination of reasons was: life-threatening+ rape (47\%), or life-threatening+ physical health (35\%), and life-threatening+ fetal impairment (17\%).

\section{Fixed effects regression models}

The univariate fixed effects regression models indicated that higher flexibility scores of abortion laws were associated with lower maternal mortality ratios (MMR). When flexibility score was fitted as a categorical variable $(0-7)$ there was evidence of a reduction in maternal mortality of between 85 and 144 per 100,000 live births for flexibility scores of three or more compared to zero. When flexibility score was fitted as a binary variable, there were 109 fewer maternal deaths per 100,000 live births $(95 \%$ CI $-133,-84)$ when the flexibility score was three or more compared to less than three.

After adjusting for GDP per capita and time intervals, the effects were slightly attenuated. However, the strong evidence that higher flexibility score of abortion laws was associated with lower MMR for all flexibility scores three or more compared to zero with the exception of flexibility score six. The estimated mean MMR was reduced in higher flexibility score group $(>=$ score 3$)$ compared to low flexibility score group (< score 3 ) by 45 after adjusting for GDP per capita and time intervals. (95\% CI: $-26,-64)$.

Including female education in the models attenuated the estimates, although the same general trend was evident. After adjusting for GDP per capita, time intervals, and female education, when the flexibility score of abortion laws was three or higher, the mean MMR was 25 maternal deaths per 100,000 births lower (95\% CI: -4, - 46) than when the flexibility score was lower than three. However, because there was a large amount of missing data on female education, the number of observations was much lower. The results of the univariate and multivariate fixed effects models are summarized in Table 3 and Table 4 respectively.

\section{Discussion}

In this large ecological study of abortion law and maternal mortality, we found that MMR decreased as a country increased its flexibility score. With the exception of a
Table 3 Univariate fixed effects regression of the association between flexibility score and maternal mortality ratio in 162 countries, $1985-2013(N=4212, n=162)$

\begin{tabular}{cccc}
\hline \multicolumn{3}{l}{ Flexibility score as a 7 level categorical variable (Baseline = Score 0) } \\
Score & Coefficient & $95 \%$ Confidence interval & $p$-value \\
Score 1 & -28 & $(-80,24)$ & 0.294 \\
Score 2 & -42 & $(-106,22)$ & 0.198 \\
Score 3 & -144 & $(-206,83)$ & $<0.001$ \\
Score 4 & -85 & $(-149,-22)$ & 0.009 \\
Score 5 & -180 & $(-240,-120)$ & $<0.001$ \\
Score 6 & -97 & $(-186,-8)$ & 0.033 \\
Score 7 & -138 & $(-197,-78)$ & $<0.001$ \\
Constant & 388 & $(336,440)$ & $<0.001$ \\
Flexibility score as a binary variable & $($ Score $<3$ versus $>=3)$ & \\
Flexibility Score $>=3$ & -109 & $(-133,-84)$ & $<0.001$ \\
Constant & 359 & $(343,376)$ & $<0.001$
\end{tabular}

Score1: abortion is legally allowed for only 1 reason, Score 2: abortion is legally allowed for 2 reasons, and so on. $\mathrm{N}=$ total no. of observations, $\mathrm{n}=$ number of countries

flexibility score of six, all countries that permitted abortion for at least one reason had lower MMR than when the flexibility score was zero. As we discuss below, this result is likely to reflect a low number of observations with this score.

When the flexibility score was modelled as a binary variable, we found that countries with a flexibility score of three or more, there were 45 less maternal deaths per 100,000 live births than when the flexibility score was less than three, after accounting for the GDP per capita and secular downward trends of maternal mortality.

Our findings that the adoption of flexible abortion laws was associated with a decrease in the countries' maternal mortality is different from one study conducted in Chile between 1957 to 2007 [13]. The Chilean study found that maternal mortality decreased after abortion became completely illegal however they adjusted for variables such as sanitation and clean water that are unlikely to be confounders. They also adjusted for the total fertility rate which is likely to be a mediator rather than a confounder [13]. Our results are consistent with previous, smaller studies conducted in Nepal, United States, Romania, South Africa, Bangladesh, and Mexico [11, 12, 15].

There are a number of explanations for the association between the flexibility of abortion laws and maternal mortality. First, when abortion is legal and accessible within the health system, the quality of abortion services is improved, and thus reducing the incidence of unsafe abortions [14]. Second, it is possible that change in total fertility rates (TFR) may play a role in influencing maternity mortality. Although the exact mechanism of the association between TFR and maternal mortality is still unknown, countries with higher TFR have higher 
Table 4 The association between flexibility of abortion laws and maternal mortality ratio after adjusting for GDP per capita and time trends, 1985-2013

$$
\begin{array}{ll}
\text { Model adjusted for GDP and Time intervals } & \text { Model adjusted for GDP, FPC, and Time interval } \\
(N=3926, n=161) & (N=1990, n=144)
\end{array}
$$

\begin{tabular}{|c|c|c|c|c|c|c|}
\hline Score & Coefficient & 95\% Confidence interval & $p$-value & Coefficient & 95\% Confidence interval & $p$-value \\
\hline Score 1 & -54 & $(-94,-14)$ & 0.008 & -13 & $(-73,48)$ & 0.681 \\
\hline Score 2 & -69 & $(-119,-20)$ & 0.006 & -26 & $(-95,43)$ & 0.454 \\
\hline Score 3 & -132 & $(-179,-85)$ & $<0.001$ & -50 & $(-116,16)$ & 0.134 \\
\hline Score 4 & -70 & $(-119,-21)$ & 0.005 & -11 & $(-75,54)$ & 0.748 \\
\hline Score 5 & -119 & $(-166,-73)$ & $<0.001$ & -65 & $(-129,-2)$ & 0.044 \\
\hline Score 6 & -17 & $(-86,51)$ & 0.622 & 2 & $(-83,87)$ & 0.965 \\
\hline Score 7 & -72 & $(-118,-26)$ & $<0.001$ & -18 & $(-79,43)$ & 0.56 \\
\hline GDP & 0.005 & $(0.004,0.005)$ & $<0.001$ & 0.004 & $(0.003,0.004)$ & $<0.001$ \\
\hline FPC & & & & -1.8 & $(-2.1,-1.4)$ & $<0.001$ \\
\hline 1990-1994* & -42 & $(-51,-33)$ & $<0.001$ & -39 & $(-50,-27)$ & $<0.001$ \\
\hline 1995-1999 & -77 & $(-86,-68)$ & $<0.001$ & -72 & $(-84,-60)$ & $<0.001$ \\
\hline 2000-2004 & -116 & $(-126,-107)$ & $<0.001$ & -96 & $(-108,-85)$ & $<0.001$ \\
\hline $2005-2009$ & -173 & $(-184,-163)$ & $<0.001$ & -134 & $(-147,-120)$ & $<0.001$ \\
\hline 2010-2013 & -220 & $(-233,-206)$ & $<0.001$ & -164 & $(-182,-147)$ & $<0.001$ \\
\hline Constant & 419 & $(379,459)$ & $<0.001$ & 492 & $(429,556)$ & $<0.001$ \\
\hline \multicolumn{7}{|c|}{ Flexibility score as a binary variable (Score $<3$ versus $>=3$ ) } \\
\hline Flexibility Score $>=3$ & -45 & $(-64,-26)$ & $<0.001$ & -25 & $(-46,-4)$ & 0.022 \\
\hline GDP & 0.005 & $(0.004,0.005)$ & $<0.001$ & 0.004 & $(0.003,0.005)$ & $<0.001$ \\
\hline FPC & & & & -2 & $(-2,-1)$ & $<0.001$ \\
\hline 1990-1994* & -42 & $(-51,-33)$ & $<0.001$ & -39 & $(-50,-27)$ & $<0.001$ \\
\hline 1995-1999 & -77 & $(-86,-68)$ & $<0.001$ & -73 & $(-84,-61)$ & $<0.001$ \\
\hline 2000-2004 & -116 & $(-126,-107)$ & $<0.001$ & -97 & $(-109,-85)$ & $<0.001$ \\
\hline 2005-2009 & -173 & $(-184,-163)$ & $<0.001$ & -135 & $(-148,-121)$ & $<0.001$ \\
\hline 2010-2013 & -219 & $(-232,-205)$ & $<0.001$ & -165 & $(-182,-148)$ & $<0.001$ \\
\hline Constant & 369 & $(356,383)$ & $<0.001$ & 485 & $(456,515)$ & $<0.001$ \\
\hline
\end{tabular}

Flexibility score as a 7 level categorical variable $($ Baseline $=$ Score 0$)$

GDP Gross Domestic Product Per Capita (US\$), FPC Female Primary Completion (Female, \%)

$\mathrm{N}=$ total number of observations, $\mathrm{n}=$ number of countries, *Baseline for five-year interval=1985-1989

maternal mortality [30]. In a national household survey in Romania, TFR reduced after the restrictive abortion law was abolished in 1989 [31]. This is supported by a recent study in Mexico, which examined the effect of elective abortion program in Mexico city in 2007 [32]. Third, some effects can be mediated through the changes in the health-seeking behaviors of women. Women with an unwanted pregnancy will seek safe abortion services if they can request abortions legally.

Our findings suggest that the liberalization of abortion laws will reduce maternal mortality. In our sample of 162 countries, 48 countries had flexibility score less than three in 2013; it is possible that maternal mortality would reduce in these countries if legal, safe abortion was more readily available. However, it is important to acknowledge that it may take years for abortion law reform to impact on maternal mortality. In fact, the change of the abortion laws itself may not be sufficient to reduce maternal mortality. Abortion law reform must also be accompanied with improved access to safe abortion services, as well as improvement in community attitudes (e.g., reduction in stigma) towards these services.

The experience of abortion law reforms in Cambodia, Colombia, Ethiopia, Mexico City, Nepal and South Africa identified some pragmatic issues in transitioning from advocacy and passage of a law to implementation. Successful implementation of abortion laws reform requires public awareness of changes in the law, clinical and administrative guidelines and dissemination to standardize delivery of medical care, and creation and uptake of safe abortion services [33]. Additionally, women need to be aware of the change in the laws and 
have knowledge of how to access the safe abortion services. A recent systematic review found that women may be unaware, or have incorrect knowledge, about abortion laws in their countries even in countries with more liberal abortion laws. [34] Therefore, it is important to develop interventions to promote accurate information after legal access to abortion has been increased.

This study has some limitations which have to be discussed. First, it is possible that abortion law does not reflect access to safe abortion. For example, in Bangladesh in 2013, the flexibility score was one because abortion was only legally allowed if the pregnancy was life- threatening for the woman. However, 'menstrual regulation' services are widely available to women in Bangladesh. 'Menstrual regulation' involves vacuum aspiration within 6 to 10 weeks of a missed menstrual period without a pregnancy test [35]. Vacuum aspiration is one of the procedures used in abortion [36]. This means that women can request abortion services legally using a different name for the service. There is also the worldwide trend change from surgical abortions towards medical abortions by misoprostol since the 1990s. The study design addresses these limitations by adjusting time-periods in the analysis. In the LatinAmerica and Caribbean countries, the decline in abortion-related maternal mortality is observed due to access to safer abortion by using misoprostol as a medical abortion despite the most-restrictive abortion laws [37]. Despite highly restrictive abortion laws, access to the medical abortion increases access to safer abortion. Therefore, we also conducted a sensitivity analysis for the fixed-effects regression models adjusted for time and GDP by excluding 24 Latin-America and Caribbean countries. The sensitivity analysis showed a stronger association between the flexibility of abortion laws and the reduction of MMR (Table 5).

The flexibility score of six was not associated with lower mortality. This may be explained by having a fewer number of countries in the flexibility score of six. For instance, there were only five countries with score six in 1985 (Barbados, Finland, Greece, India, and Luxembourg) where there were only seven countries with score six in 2013 (Barbados, Finland, India, Fiji, Iceland, Luxembourg, and St. Vincent and the Grenadines). So, there is a possibility that the regression models did not have enough power to detect the difference between the two groups due to a relatively fewer number of countries in score six. Additionally, we did not have any information on some of the key variables. For example, there was no reliable data on gender equity which is likely to be a confounder. There was attenuation of the estimates when female primary completion rate was included in the models however $50 \%$ of data was missing for this variable (i.e. 50\%).
Table 5 The results of sensitivity analysis $(N=3309, n=137)$ Flexibility score as a 7 level categorical variable (Baseline $=$ Score 0 )

$\begin{array}{clll}\text { Score } & \text { Coefficient } & 95 \% \text { Confidence interval } & p \text {-value } \\ \text { Score 1 } & -141 & (-220,-61) & 0.001 \\ \text { Score 2 } & -149 & (-235,-63) & 0.001 \\ \text { Score 3 } & -253 & (-338,-168) & <0.001 \\ \text { Score 4 } & -172 & (-261,-83) & <0.001 \\ \text { Score 5 } & -232 & (-317,-146) & <0.001 \\ \text { Score 6 } & -146 & (-254,-38) & 0.008 \\ \text { Score 7 } & -197 & (-283,-111) & <0.001 \\ \text { GDP } & 0.005 & (0.004,0.005) & <0.001 \\ \text { 1990-1994 } & -47 & (-57,-36) & <0.001 \\ \text { 1995-1999 } & -86 & (-96,-75) & <0.001 \\ \text { 2000-2004 } & -130 & (-141,-120) & <0.001 \\ \text { 2005-2009 } & -196 & (-208,-184) & <0.001 \\ \text { 2010-2013 } & -249 & (-264,-233) & <0.001 \\ \text { Constant } & 564 & (484,643) & <0.001\end{array}$

Flexibility score as a binary variable (Score $<3$ versus $>=3$ )

$\begin{array}{llll}\text { Flexibility Score }>=3 & -82 & (-106,-57) & <0.001 \\ \text { GDP } & 0.005 & (0.005,0.006) & <0.001 \\ 1990-1994 & -47 & (-58,-37) & <0.001 \\ 1995-1999 & -87 & (-98,-76) & <0.001 \\ 2000-2004 & -132 & (-143,-121) & <0.001 \\ 2005-2009 & -198 & (-210,-185) & <0.001 \\ 2010-2013 & -248 & (-263,-233) & <0.001 \\ \text { Constant } & 432 & (415,449) & <0.001\end{array}$

GDP Gross Domestic Product Per Capita (US\$)

$\mathrm{N}=$ total no. of observations, $\mathrm{n}=$ number of countries Adjusted for Time and GDP

This study has a number of important strengths. As far as we are aware this is the most comprehensive study of abortion law and maternal mortality ever conducted. We had a large sample of 162 countries over a 28 -year time period, which included high, medium and low- income countries. We used an ecological study design the most appropriate study design when ecological effects are of interest. An ecological study is particularly relevant when the level of inference is ecologic rather than individual, and when evaluating the effects of social processes or population interventions such as new programs, policies, or legislation [38].

Our use of fixed effects regression models is a significant advance. Fixed effects regression models allowed us to control for the possible confounding associated with country effects and reduce omitted variable bias [26] due to time-invariant variables. In contrast to previous studies [12, 15], we attempted to adjust for time-varying confounding by including GDP per capita and five-year time periods. 


\section{Conclusion}

In conclusion, our study demonstrates that maternal mortality is lower when abortion laws are less restrictive. Our results suggest that there is a need to reform abortion laws in the countries with the most restrictive abortion laws, and to provide safe abortion services to protect women from unsafe and illegal abortions. To improve our understanding of the associations between abortion law and maternal mortality and other women's health issues we recommend that key country-level variables such as contraceptive prevalence, female education and gender equity are systematically recorded.

\section{Additional files}

Additional file 1: Table summarizing the specific reasons for legal abortion for each flexibility score. This table describes a summary for the specific reasons allowed for legal abortions in each flexibility score (0-7). (DOCX $50 \mathrm{~kb}$ )

Additional file 2: Glossary and Definitions. Glossary and Definitions for the Uncertainty Interval, maternal mortality ratio (MMR), Maternal Death, and Live Birth. (DOCX 33 kb)

Additional file 3: Maternal Mortality Ratios (Mean) and the flexibility score of abortion laws (Mean score) in the sample countries, 1985-2013. Description of Data: The table summarizes the average score for abortion laws and average maternal mortality ratios for each sample country from 1985 to 2013. (DOCX 37 kb)

Additional file 4: List of Latin-American and Caribbean Countries excluded for Sensitivity Analysis. The list provides the name of 24 LatinAmerica and Caribbean countries which has been excluded to conduct sensitivity analysis. (DOCX $35 \mathrm{~kb}$ )

\section{Abbreviations}

GDP per capita: Gross domestic product per capita; MMR: Maternal mortality ratio; SDG: Sustainable development goals; TFR: Total fertility rate; UI: Uncerntainty interval; UN: United Nations; WHO: World Health Organization

\section{Acknowledgements}

Not applicable

\section{Funding}

There is no funding source applicable for this research work.

\section{Availability of data and materials}

The data for maternal mortalities and abortion laws can be assessed and extracted publicly free of charge at http://www.who.int/gho/ maternal_health/mortality/maternal/en/ http://www.un.org/en/development/desa/population/publications/policy/ world-abortion-policies-2013.shtml.

The datasets used and analyzed during the current study are available from the corresponding author on reasonable request.

\section{Consent for publication}

Not applicable

\section{Authors contributions}

All authors participated in designing the study and developing a hypothesis. SM extracted the data and analyzed and interpreted the data. AM supported the data analysis and the interpretation and writing the manuscript. Professor AK involved in the design of the study, checking the dataset, and interpreted the data. All authors involved in writing the manuscript and proofreading and revising it for the journal submission. All authors read and approved the final manuscript.

\section{Ethics approval and consent to participate}

Not applicable. All data collection and analysis were performed at the country level. No patients were involved at any stage of the study. There was no ethical approval requirement for this study according to the Human Ethics Advisory Group of the University of Melbourne.

\section{Competing interests}

The work in this research project was undertaken to partially fulfill the requirements of The University of Melbourne's Master of Public Health degree. The views expressed herein are those of the author(s) and may not reflect the views of The University of Melbourne or the United Nations Population Funds. The authors declare that they have no competing interests.

\section{Publisher's Note}

Springer Nature remains neutral with regard to jurisdictional claims in published maps and institutional affiliations.

\section{Author details}

'Melbourne School of Population and Global Health, The University of Melbourne, Melbourne, Australia. ${ }^{2}$ Centre for Health Equity, Melbourne School of Population and Global Health, University of Melbourne, Melbourne, Australia.

Received: 19 February 2018 Accepted: 25 December 2018

Published online: 05 January 2019

\section{References}

1. World Health Organization, Unicef. Trends in maternal mortality: 1990-2015: estimates from WHO, UNICEF, UNFPA, World Bank Group and the United Nations Population Division. 2015.

2. Say L, Chou D, Gemmill A, Tunçalp Ö, Moller A-B, Daniels J, et al. Articles: global causes of maternal death: a WHO systematic analysis. Lancet Glob Health. 2014:2:e323-e33.

3. Haddad LB, Nour NM. Unsafe abortion: unnecessary maternal mortality. Rev. 2009:2(2):122-6.

4. Becker B. 78,000 women die each year from unsafe abortions worldwide. It is estimated that there are 20 million unsafe abortions per year on a global basis. Reprod Freedom News. 1999;8(3):1-5.

5. Faundes A. Unsafe abortion. Health impact. Journal of perinatal medicine conference: 10th world congress of perinatal Medicine 2011;39(no pagination)

6. Adinma E. Unsafe abortion and its ethical, sexual and reproductive rights implications. West Afr J Med. 2011;30(4):245-9.

7. Grimes DA, Benson J, Singh S, Romero M, Ganatra B, Okonofua FE, et al. Series: unsafe abortion: the preventable pandemic. Lancet. 2006;368:1908-19.

8. WHO. Unsafe abortion: global and regional estimates of the incidence of unsafe abortion and associated mortality in 2008. In: Geneva; 2011.

9. Singh S. Hospital admissions resulting from unsafe abortion: estimates from 13 developing countries. Lancet. 2006;368(9550):1887-92.

10. United Nations Population D. Abortion Policy and Reproductive Health around the World. 2014

11. Henderson JT, Puri M, Blum M, Harper CC, Rana A, Gurung G, et al. Effects of abortion legalization in Nepal, 2001-2010. PLoS One. 2013;8(5):1-7.

12. Benson J, Andersen K, Samandari G. Reductions in abortion-related mortality following policy reform: evidence from Romania, South Africa and Bangladesh. Reprod Health. 2011:8:39.

13. Koch E. Impact of reproductive laws on maternal mortality: the chilean natural experiment. Linacre Q. 2013;80(2):151-60.

14. Faundes $\mathrm{A}$, Shah $\mathbb{H}$. Evidence supporting broader access to safe legal abortion. Int J Gynaecol Obstet. 2015;131(Suppl 1):S56-9.

15. Tietze $C$. The public health effects of legal abortion in the United States. Fam Plan Perspect. 1984;16(1):26-8.

16. Okonta PI, Ebeigbe PN, Sunday-Adeoye I. Liberalization of abortion and reduction of abortion related morbidity and mortality in Nigeria. Acta Obstet Gynecol Scand. 2010;89(8):1087-90.

17. World Abortion Policies 2013: United Nations, Department of Economic and Social Affairs, Population Division [Available from: http://www.un.org/en/ development/desa/population/publications/policy/world-abortion-policies2013.shtml. 
18. Maternal Mortality, Global Health Observatory Data: World Health Organization [Available from: http://www.who.int/gho/maternal_health/ mortality/maternal/en/.

19. United Nations. DoEaSA, population, division. In: Abortion policies and reproductive health around the world; 2014.

20. Gerdts C, Vohra D, Ahern J. Measuring unsafe abortion-related Mortality: a systematic review of the existing methods. PLoS One. 2013;8(1):1-14.

21. Female Primary Completion Rate. 1985-2013.The World Bank [Available from: http://data.worldbank.org/indicator/SE.PRM.CMPT.FE.ZS.

22. Female Literacy Rate. 1985-2013. The World Bank [Available from: http:// data.worldbank.org/indicator/SE.ADT.LITR.ZS.

23. Health Expenditure per Capita. 1985-2013. The World Bank [Available from: https://data.worldbank.org/indicator/SH.XPD.CHEX.PC.CD]

24. Gross Domestic Product per Capita.1985-2013. The World Bank; [Available from: http://data.worldbank.org/indicator/NY.GDP.PCAP.CD.

25. Halaby CN. Panel models in sociological research. Theory Pract. 2004;507.

26. Allison PD. Fixed effects regression models. [electronic resource]: Los Angeles, [Calif.] ; London : SAGE. In: c2009; 2009.

27. Ke X, Saksena P, Holly A. The determinants of health expenditure: a countrylevel panel data analysis: World Health Organization; 2011.

28. Milner A, McClure R, Sun J, De Leo D. Globalisation and suicide: an empirical investigation in 35 countries over the period 1980-2006. Health Place. 2011 17:996-1003.

29. Bole V. Rebec Ppres. Bootstrapping the Hausman test in panel data models. Commun Stat Simul Comput. 2013;42(3):650-70.

30. Sonneveldt E, Plosky WDC, Stover J. Linking high parity and maternal and child mortality: what is the impact of lower health services coverage among higher order births? BMC Public Health. 2013;13(Suppl 3).

31. Florina Serbanescu, Leo Morris, Paul Stupp, Stanescu A. The impact of recent policy changes on fertility, abortion, and contraceptive use in Romania Stud Fam Plann 1995:26(2):76-87.

32. Damian Clarke, Mühlrad H. The Impact of Abortion Legalization on Fertility and Maternal Mortality: New Evidence from Mexico. Working Papers In Economics (Online). 2016.

33. Institute G. Making abortion services accessible in the wake of legal reforms: a framework of six case studies. New York Guttmacher Institute; 2012.

34. Assifi AR, Berger B, Oz T, Khosla R, Ganatra B. Women's awareness and knowledge of abortion Laws: a systematic review. PLoS One. 2016;11(3):1-14

35. Syeda NMC, Moni D. A situation analysis of the menstrual regulation Programme in Bangladesh. Reproductive Health Matters. 2004;12(24):95-104.

36. WHO. Safe abortion : technical and policy guidance for health systems Geneva: World Health Organization 2012.

37. Dzuba IG, Winikoff B, Peña M. Medical abortion: a path to safe, high-quality abortion care in Latin America and the Caribbean. Eur J Contracept Reprod Health Care. 2013;18(6):441-50

38. Kenneth J Rothman, Sander Greenland, Lash TL. Modern Epidemiology Third Edition ed: Lippincott Williams \& Wilkins; 2012. 758 p.

Ready to submit your research? Choose BMC and benefit from:

- fast, convenient online submission

- thorough peer review by experienced researchers in your field

- rapid publication on acceptance

- support for research data, including large and complex data types

- gold Open Access which fosters wider collaboration and increased citations

- maximum visibility for your research: over $100 \mathrm{M}$ website views per year

At $\mathrm{BMC}$, research is always in progress.

Learn more biomedcentral.com/submissions 